C2016, Elsevier. Licensed under the Creative Commons AttributionNonCommercial-NoDerivatives 4.0 International http://creativecommons.org/ about/downloads 


\title{
Markers of Anthropogenic Contamination: A Validated Method for Quantification of Pharmaceuticals, Illicit Drug Metabolites, Perfluorinated Compounds and Plasticisers in Sewage Treatment Effluent and Rain Runoff
}

\author{
John L. Wilkinson ${ }^{1 *}$, Julian Swinden ${ }^{2}$, Peter S. Hooda ${ }^{1}$, James Barker ${ }^{2}$ and Stephen Barton ${ }^{2}$ \\ ${ }^{1}$ School of Natural and Built Environments, Kingston University London, Kingston-upon-Thames, Surrey, United Kingdom \\ ${ }^{2}$ School of Life Sciences, Pharmacy and Chemistry, Kingston University London, Kingston-upon-Thames, Surrey, United Kingdom \\ *Corresponding Author: j.wilkinson@kingston.ac.uk, Kingston University London, Penrhyn Road Main Building, Room 2021, Kingston- \\ Upon-Thames, Surrey, U.K.
}

Corresponding Author: John L. Wilkinson, j.wilkinson@kingston.ac.uk, Kingston University London, Penrhyn Road Campus, Kingston-upon-Thames, Surrey, U.K., KT1 2EE

Competing financial interests declaration: Nothing to declare

Conflict of interests:

Journal of publication:

Nothing to declare

Volume:

Chemosphere

Pages:

159, September 2016

Published online:

638-646

DOI:

10.1016/j.chemosphere.2016.06.039

\begin{abstract}
An effective, specific and accurate method is presented for the quantification of 13 markers of anthropogenic contaminants in water using solid phase extraction (SPE) followed by high performance liquid chromatography (HPLC) tandem mass spectrometry (MS/MS). Validation was conducted according to the International Conference on Harmonisation (ICH) guidelines. Method recoveries ranged from $77-114 \%$ and limits of quantification between $0.75-4.91 \mathrm{ng} / \mathrm{L}$. A study was undertaken to quantify the concentrations and loadings of the selected contaminants in 6 sewage treatment works (STW) effluent discharges as well as concentrations in 5 rain-driven street runoffs and field drainages. Detection frequencies in STW effluent ranged from 25\% (ethinylestradiol) to 100\% (benzoylecgonine, bisphenol-A (BPA), bisphenol-S (BPS) and diclofenac). Average concentrations of detected compounds in STW effluents ranged from $3.62 \mathrm{ng} / \mathrm{L}$ (ethinylestradiol) to $210 \mathrm{ng} / \mathrm{L}$ (BPA). Levels of perfluorinated compounds (PFCs) perfluorooctanoic acid (PFOA) and perfluorononanoic acid (PFNA) as well as the plasticiser BPA were found in street runoff at maximum levels of $1160 \mathrm{ng} / \mathrm{L}, 647 \mathrm{ng} / \mathrm{L}$ and $2405 \mathrm{ng} / \mathrm{L}$ respectively $(8.52,3.09$ and 2.7 times more concentrated than maximum levels in STW effluents respectively). Rain-driven street runoff may have an effect on levels of PFCs and plasticisers in receiving rivers and should be further investigated. Together, this method with the 13 selected contaminants enables the quantification of various markers of anthropogenic pollutants: inter alia pharmaceuticals, illicit drugs and their metabolites from humans and improper disposal of drugs, while the plasticisers and perfluorinated compounds may also indicate contamination from industrial and transport activity (street runoff).
\end{abstract}

\section{Acknowledgements}

This research was funded with thanks by Kingston University London 


\section{Introduction}

From the turn of the $21^{\text {st }}$ century, the occurrence, fate and environmental toxicity of pharmaceuticals and other so-called emerging contaminants in the aquatic environment (rivers, reservoirs, oceans and drinking water) has been the subject of many studies (e.g., Kolpin et al., 2002; Vajda et al., 2008; 2011; Llorca et al. 2012) and reviews (e.g., Petrie et al., 2015; Wilkinson et al., 2015). Nearly every human and veterinary pharmaceutical has been detected in the aquatic environment, typically at sub- $\mu \mathrm{g} / \mathrm{L}$ concentrations. Evidence suggests that once in the aquatic environment, residues of some pharmaceuticals and other emerging contaminants (ECs) cause biological disruption/dysfunction in exposed non-target organisms via mechanisms such as endocrine dysfunction (Woodling et al., 2006; Vajda et al., 2008; Patisaul et al., 2009; Vajda et al., 2011). Once administered, pharmaceuticals are rarely, if ever, completely metabolised in the body and are directed to sewage treatment works (STWs) via urinary and biliary fecal excretions (Jjemba, 2006; Silva et al., 2011). Residues of pharmaceuticals typically enter the aquatic environment through STW effluent outfalls where many compounds do not completely degrade (Verlicchi et al., 2012). Other anthropogenic contaminants such as musk compounds used in fragrances and lotions, surfactants, and ultraviolet filters in sunscreen are also directed to STWs via wastewater (Peck, 2006; Roosens et al., 2007). Supplementary Table 1 shows concentrations of 21 pharmaceuticals and other emerging contaminants which are typically detected in river water.

Emerging contaminants are commonly defined as any compound (both synthetic and natural) in the environment whose presence is not routinely monitored and shows the potential to cause ecological disruption (Raghav et al., 2013; United States Geological Survey, 2014). Among such ECs are perfluorinated compounds (PFCs) such as perfluorooctanoic acid (PFOA), perfluorononanoic acid (PFNA), perfluorobutane sulfonic acid (PFBS), and perfluorooctane sulfonate (PFOS) as well as plasticisers including bisphenol-A (BPA) and bisphenol-S (BPS) among others. Plasticisers are commonly used to modify the rigidity of plastic materials and are used in product and food packaging, manufacture of polycarbonate plastic, thermal receipt paper, water pipes, epoxy resins, vinyl floors, car tires, among many others (U.S. Food and Drug Administration, 2015). Perfluorinated compounds are commonly used in waterproofing agents, polishes, waxes, nonstick cookware and cleaning products (Posner, 2012). ECs such as plasticisers and PFCs are also known to enter the aquatic environment through STW effluent outfalls (Meyer and Bester, 2004; Zhang et al., 2013). 
Biodegradation of PFC precursor molecules during sewage treatment into other PFCs is suggested to increase their effluent concentrations by 32-290 times over that in the influent (Zhang et al., 2013). For example, Zhang et al. (2013) reported that of 28 sampled STWs in economically developed areas of China, effluent concentrations of PFOA were higher than influent $81 \%$ of the time, $69 \%$ of the time for perfluorononanoic acid (PFNA), $57 \%$ of the time for perfluorobutane sulfonic acid (PFBS) and 58\% of the time for PFOS. Precursor molecules found in STW influent include N-ethyl perfluorooctane sulphonamide, which degrades into PFOS and fluorotelomer alcohols (e.g., 8:2 fluorotelomer alcohol) which degrade into PFOA (Zhang et al., 2012; Avendaño and Liu, 2015).

Recent evidence indicates that PFCs may be introduced into the aquatic environment through non-point sources, such as runoff from streets (Zushi et al., 2008; Murakami et al., 2009; Furl et al., 2011). Zushi et al. (2008) reported concentrations of PFCs 2-11 times higher in rain runoff than in the effluent outfalls of three studied STWs along the Tsurumi River (Yokohama City, Kanagawa Prefecture, Japan). Despite evidence of PFCs introduced to the aquatic environment through runoff, there are limited studies quantifying similar contributions of other ECs, such as plasticisers. Furthermore, studies comparing STW effluent to runoff contributions of PFCs and plasticisers into the same river system is limited.

Here, a validated method is presented to accurately and specifically quantify 13 markers of anthropogenic contamination in fresh water: inter alia pharmaceuticals, illicit drugs and their metabolites. Pharmaceuticals and illicit drugs are specific indicators of human-derived contamination and improper disposal of drugs, while the plasticisers and perfluorinated compounds also indicate contamination from industrial and transport activity (street runoff). The presented method can be used to efficiently and specifically quantify concentrations of contaminants of human, industrial and transportation origins. A key feature of this method is the achievement of adequate detection limits using a relatively small amount of water $(200 \mathrm{~mL})$ for analysis. Here, increased ease of sample transport (due to the small volume of water required) enables analysis of a greater number of samples in relatively little time. The sensitivity/detection limits of the method proposed as such can be further increased by increasing the amount of sample water used in solid phase extraction (SPE). The developed method enabled a comparison between contaminant inputs into selected rivers via sewage treatment effluent and runoff from both streets and fields.

\section{Materials and Methods}

\subsection{Standards and Reagents}


Thirteen compounds were selected for analysis including pharmaceuticals: ethinylestradiol, acetaminophen and diclofenac, illicit drugs and metabolites: methamphetamine and its metabolite amphetamine and benzoylecgonine (metabolite of cocaine), plasticisers: bisphenol-S (BPS), bisphenol-A (BPA) and its biotransformation product 4'-hydroxyacetophenone (HAP), perfluorinated compounds: PFOA, PFOS, PFNA, and PFBS, and deuterated internal standards: BPA-D16, acetominophen-D4 and methamphetamine-D5. All compounds were purchased from Sigma Aldrich (Gillingham, Dorset, U.K.) and were of $96 \%$ purity or higher. PFOS was purchased as a potassium salt and benzoylecgonine was tetrahydrated. Strata-X $33 \mu \mathrm{m}$ polymeric reversed phase $200 \mathrm{mg} / 6 \mathrm{~mL}$ SPE cartridges were purchased from Phenomenex (Macclesfield, Cheshire, U.K.). A Phenomenex Kinetex 2.6u C18 150x2.1mm chromatography column using a SecurityGuard ULTRA UHPLC C18 2.1mm guard column was purchased from Phenomenex (Macclesfield, Cheshire, U.K.). Whatman GF/F-grade glass microfiber filters (diameter $47 \mathrm{~mm}$, pore size 0.7 $\mu \mathrm{m})$ were purchased from Fisher Scientific (Loughborough, Leicestershire, U.K.).

Stock solutions were prepared for each compound and internal standards at a concentration of $1000 \mathrm{mg} / \mathrm{L}$ in LCMS-grade acetonitrile except for PFOS, diclofenac and ethinylestradiol, which were prepared at $1000 \mathrm{mg} / \mathrm{L}$ in HPLC grade acetone. A mixed solution was made in LCMS-grade acetonitrile to a concentration of $5 \mathrm{mg} / \mathrm{L}$ for all analytes except BPA at $30 \mathrm{mg} / \mathrm{L}$, ethinylestradiol at $25 \mathrm{mg} / \mathrm{L}$, and HAP at $7.5 \mathrm{mg} / \mathrm{L}$ which was further diluted into working solutions. Concentrations of target analytes in the mixed solution were optimised based on spectrometer sensitivity to each respective compound. Solutions were stored in $10 \mathrm{~mL}$ borosilicate glass volumetric flasks at $4^{\circ} \mathrm{C}$ in the dark and renewed monthly. A mixture of all compounds at $100 \mathrm{ng} / \mathrm{L}$ was analysed via HPLC-MS/MS once per week for 4-weeks to ensure no significant degradation occurred during monthly use of standard solutions.

\subsection{Sample Collection}

Effluent samples $(n=12)$ were collected in duplicate from six STWs along three rivers in the south east of England (Hogsmill, Bourne and Blackwater: Supplementary Table 2). Runoff samples were collected from grass field drainage $(n=3)$ and street runoff $(n=2)$ during periods of rainfall (Supplementary Table 3).

Grab samples were collected $(200 \mathrm{~mL})$ in amber glass bottles. All bottles were washed three times with $50 / 50$ acetonitrile:acetone $(\mathrm{v} / \mathrm{v})$ followed by three washes with milli-Q water and were rinsed with sample water before collection. Water samples were collected from 
STW effluent outfalls and drainage pipes (both field and street) directly prior to entering the river flow. After collection, samples were stored at $4^{\circ} \mathrm{C}$ in the dark until vacuum filtration (within $8 \mathrm{~h}$ of collection) using GF/F glass membrane filters. Membrane filters were soaked in $10 \%$ nitric acid for 12 hours (to degrade any organic compounds within or on the filter) followed by three rinses under vacuum filtration with 50:50 acetonitrile:acetone $(\mathrm{v} / \mathrm{v})$ and three rinses with HPLC water. All samples were extracted before analysis using the SPE procedure described in Section 2.3 within $24 \mathrm{~h}$ of collection.

\subsection{Solid Phase Extraction}

Solid Phase Extraction (SPE) of $200 \mathrm{~mL}$ sample water was carried out using

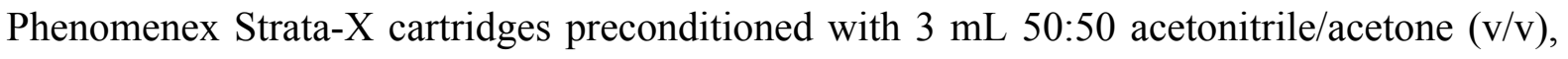
washed with $3 \mathrm{~mL}$ HPLC-grade $\mathrm{H}_{2} \mathrm{O}$ and loaded at a rate of $5 \mathrm{~mL} / \mathrm{min}$. Loaded cartridges were dried under vacuum for $15 \mathrm{~min}$ and eluted with $2 \times 7 \mathrm{~mL}$ aliquots of 50:50 acetonitrile/acetone $(\mathrm{v} / \mathrm{v})$ at a rate of $1 \mathrm{~mL} / \mathrm{min}$. Extracts were evaporated to dryness using rotary evaporation and reconstituted with $1 \mathrm{~mL}$ of (80:20 $\mathrm{HPLC}_{2} \mathrm{O}$ /acetonitrile, v/v) spiked with internal standards to $25 \mathrm{ng} / \mathrm{mL}$.

\subsection{HPLC-MS/MS Analysis}

Extracts were analysed by HPLC-MS/MS using an Agilent Technologies 1260 Infinity HPLC and an Agilent Technologies 6430 series triple quadrupole mass spectrometer operated in multiple reaction monitoring (MRM) mode. Adequate separation was obtained at a flow rate of $0.2 \mathrm{~mL} / \mathrm{min}$ with a solvent gradient starting at 80:20 $\mathrm{H}_{2} \mathrm{O} /$ acetonitrile $(\mathrm{v} / \mathrm{v})$ reducing to 35:65 $\mathrm{H}_{2} \mathrm{O}$ /acetonitrile (v/v) at 15 min which returned to $80: 20 \mathrm{H}_{2} \mathrm{O}$ /acetonitrile (v/v) at 15.1 min, where it remained until the end of the run at $19.5 \mathrm{~min}$ (Figure 1). Collision energy, fragmentor and electron multiplier voltage were optimised for two transition ions per target analyte and internal standard using electrospray ionisation (Table 1). An electron multiplier voltage of $+/-350 \mathrm{~V}$ was used for every target compound. A capillary voltage of $+/-4000 \mathrm{~V}$, chamber current of $0.12 \mu \mathrm{A}$, nebuliser pressure of $30 \mathrm{psi}$, gas temperature of $325^{\circ} \mathrm{C}$ and gas flow of $12 \mathrm{~L} / \mathrm{min}$ were used for mass spectrometry. An injection volume of $10 \mu \mathrm{L}$ was used for all analysis. Quantification was achieved using a 9-point blank-offset and internal standard-corrected calibration (calibration points also underwent SPE) calculated by linear regression analysis in Agilent MassHunter Workstation Software: Quantitative Analysis (version B.04.00/Build 4.0.225.19). Calibration standards and blanks also underwent SPE and were used to normalise for recoveries. The method was validated using the $\mathrm{ICH}$ 
Harmonised Tripartite Guideline for Validation of Analytical Procedures: Q2(R1) Text and Methodology (ICH, 2005).

\subsection{Method Validation and Quality Assurance}

\subsubsection{Specificity}

Specificity was assessed by spiking river water collected from the Rowhill Nature Reserve (source of the Blackwater River) with a mixture of all selected PPCPs/ECs at a concentration of $100 \mathrm{ng} / \mathrm{L}$. Spiked sample chromatograms were compared to those of nonspiked water samples and assessed for the presence of interfering peaks at the specific retention time of known target compounds.

\subsubsection{Intra-/Inter-day Precision/Repeatability}

Repeatability and precision were determined using the relative standard deviation (RSD) calculated from replicate extractions of spiked HPLC water subjected to SPE. Intraday (intermediate) precision was calculated at two concentrations, $25 \mathrm{ng} / \mathrm{L}(\mathrm{n}=3)$ and 100 $\mathrm{ng} / \mathrm{L}(\mathrm{n}=3)$ every day over 3 days (6 determinations/day). Inter-day precision (repeatability) was calculated at two concentrations, $25 \mathrm{ng} / \mathrm{L}(\mathrm{n}=6)$ and $100 \mathrm{ng} / \mathrm{L}(\mathrm{n}=6)$. Each sample was analysed three times by HPLC-MS/MS in triplicate and averages are reported in Table 2.

\subsubsection{Accuracy}

Method accuracy was evaluated by spiking $200 \mathrm{~mL}$ HPLC-grade water with a mix of analytes at three concentrations followed by solid phase extraction and analysis (triplicate analysis, 9 total determinations). Three concentrations of mixed analytes selected were: 10 $\mathrm{ng} / \mathrm{L}$ ( $\mathrm{n}=3$ replicates), $50 \mathrm{ng} / \mathrm{L}$ ( $\mathrm{n}=3$ replicates) and $100 \mathrm{ng} / \mathrm{L}(\mathrm{n}=3$ replicates). Spiked water was subjected to the same treatment as experimental samples (SPE followed by rotary evaporation and reconstitution in $1 \mathrm{~mL}$ mobile phase before HPLC-MS/MS analysis). Replicates were offset by a procedural blank of $200 \mathrm{~mL}$ HPLC-water (stored in an identical beaker as the accuracy replicates) subjected to SPE, rotary evaporation and reconstitution. The absolute value of the difference between the observed/calculated concentrations and the known spiked concentration are presented as accuracy (Table 3).

\subsubsection{Recovery}

Recovery was evaluated by spiking $200 \mathrm{~mL}$ HPLC-grade water with two concentrations of all (mixed) analytes: $50 \mathrm{ng} / \mathrm{L}(\mathrm{n}=3$ replicates) and $100 \mathrm{ng} / \mathrm{L}$ ( $\mathrm{n}=3$ replicates). Spiked HPLC water was subjected to the same treatment as experimental samples (SPE followed by rotary evaporation and reconstitution in $1 \mathrm{~mL}$ mobile phase before HPLCMS/MS analysis). Samples were analysed in triplicate and analyte concentrations calculated using linear regression with calibration points having also undergone SPE. Calculated analyte 
concentrations were divided by the known spiked concentration and multiplied by 100 to yield \% recovery (Table 3). HPLC water was selected to evaluate recoveries over spiked matrix (STW effluent) due to the high variability of selected contaminant levels found between studied STW effluent outfalls.

\subsubsection{Linearity}

Linearity was assessed through calibration curve $r^{2}$-values using linear regression analysis with the aim of attaining $\mathrm{r}^{2}$-values $>0.95$. Analyte-spiked $200 \mathrm{~mL}$ aliquots of HPLC water were subjected to SPE followed by rotary evaporation and reconstitution in $1 \mathrm{~mL}$ mobile phase before HPLC-MS/MS analysis. The spiked HPLC-water concentrations ranged from 1-500 ng/L for ethinylestradiol, 0.6-300 ng/L for BPA, 0.3-150 ng/L for HAP and 0.2$100 \mathrm{ng} / \mathrm{L}$ for all other compounds (Supplementary Table 4).

\subsubsection{Limit of detection/quantification}

Both the limit of detection (LOD) and limit of quantification (LOQ) were determined using a signal-to-noise approach. A $100 \mathrm{~mL}$ aliquot of HPLC-grade water was spiked (preSPE) with analyte masses equal to that in the lowest calibration level (BPA $1.2 \mathrm{ng} / \mathrm{L}$, ethinylestradiol $1.0 \mathrm{ng} / \mathrm{L}$, hydroxyacetophenone $0.3 \mathrm{ng} / \mathrm{L}$ and all others $0.2 \mathrm{ng} / \mathrm{L}$ ). SPE

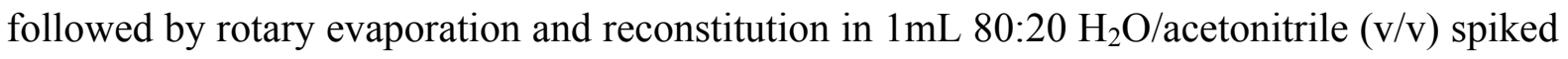
with internal standards was conducted prior to HPLC-MS/MS analysis. A total of ten replicates were used for the determination of LOD and LOQ. LOD and LOQ were determined as the compound's concentration that yielded a mean signal-to-noise ratio of 3:1 and 10:1 respectively $(n=10)$. Where such $S / N$ values were not determined at the lowest calibration level, identical replicate analysis was performed at increasing concentrations until adequate $\mathrm{S} / \mathrm{N}$ ratios were found (Table 3 ).

\subsubsection{Calibration and quantitative analysis}

A 9-point internal standard-corrected and blank offset calibration curve was determined for each analyte just before field sample extraction and analysis on every sample collection day. Calibration points were assessed by spiking $200 \mathrm{~mL}$ aliquots of HPLC-grade water to the concentrations in Supplementary Information Table 4. All calibration and blank samples were subjected to the same storage, solid phase extraction, rotary evaporation and reconstitution methods/conditions as experimental samples explained in sections 2.2-2.4. Using this method, background levels of any potential method-derived contamination was offset in each calibration and further offset by a procedural blank. Linear regression analysis was performed using Agilent MassHunter Workstation Software: Quantitative Analysis (version B.04.00/Build 4.0.225.19). The calibrated range was compound-specific: 1-500 ng/L 
for ethinylestradiol, 0.6-300 $\mathrm{ng} / \mathrm{L}$ for BPA, 0.3-150 ng/L for hydroxyacetophenone and 0.2$100 \mathrm{ng} / \mathrm{L}$ for all other compounds (Supplementary Table 4).

\subsubsection{Quality Assurance and Procedural Blanks}

Throughout the development and application of the presented method, great care was given to quality, accuracy, and cleanliness. Extracts of environmental samples were always injected into the LCMS in triplicate. After every six injections a standard quality control SPE-extract (200 mL HPLC-water spiked to $100 \mathrm{ng} / \mathrm{L}$ of each analyte) was run to check instrument parameters and ensure accurate quantification. All glassware was, without exception, rinsed three times with a mixture of acetonitrile:acetone $(50: 50, \mathrm{v} / \mathrm{v})$ between every use except for round bottom flasks used in rotary evaporation which were additionally first scrubbed with water and soaked in $10 \%$ nitric acid for $16 \mathrm{~h}$ between uses. Volumetric flasks used to store solutions were dedicated to specific compounds or mixtures as to avoid cross-contamination. Laboratory workspaces were cleaned before and after every use and the laboratory itself was thoroughly cleaned on a weekly basis.

Procedural blanks were used throughout method validation and quantitative analysis. Blanks underwent the same sample storage, solid phase extraction, rotary evaporation and reconstitution as all calibration points and field samples. For example, procedural blanks used in calibration and quantitative analysis were created using $200 \mathrm{~mL}$ HPLC-water stored in the same 3-times solvent rinsed amber glass bottles as field samples and stored in the dark at $4^{\circ}$ C until solid phase extraction followed by rotary evaporation of SPE extract, reconstitution and HPLC-MS/MS analysis. The only difference between these procedural blanks and true field blanks was that they did not undergo the sample collection step (capturing of water from the effluent outfall). Similarly, the $200 \mathrm{~mL}$ HPLC-water used for validation blanks were stored in the same solvent rinsed beakers and followed identical handling procedures as respective validation replicates (per standard good laboratory practice). Use of blanks in method validation followed that outlined in the ICH Q2(R1) Text and Methodology (ICH, 2005). Analysis was carried out to determine levels of target analytes in blanks relative to a calibration of standard samples (not undergoing identical SPE, storage and handling procedures). Of the thirteen target contaminants, only two were detected in procedural blanks used for quantitative analysis $(n=3)$. Here, BPA was detected below the LOQ and hydroxyacetophenone was detected at $1.22 \mathrm{ng} / \mathrm{L}$ on average. In procedural blanks used for method validation, only hydroxyacetophenone was detected and was consistently found below the LOQ $(n=3)$. It should be noted that all calibration points used for quantitative 
analysis underwent the same handling procedures and sample treatment as field samples and were blank offset.

\section{Results}

\subsection{Method Validation}

Validation results are tabulated in Tables 2 and 3 and a brief description is included in this section.

All intra-day (intermediate precision) RSD-values were below $10 \%$ except for methamphetamine at $25 \mathrm{ng} / \mathrm{L}(10.1 \%$ on day 3$)$ and $100 \mathrm{ng} / \mathrm{L}(12.5 \%$ day 1 and $13.7 \%$ day 3), acetaminophen at $25 \mathrm{ng} / \mathrm{L}(12.2 \%$ on day 3) and 4'-hydroxyacetophenone at $25 \mathrm{ng} / \mathrm{L}$ (10.5\% day 2 and $12.3 \%$ day 3 ). Inter-day (repeatability) RSD-values were consistently below $10 \%$ except for methamphetamine at $100 \mathrm{ng} / \mathrm{L}(11.8 \%)$. Table 2 shows average repeatability and intra-day precision data.

Method accuracy was determined to be within $\pm 0.03-2.15 \mathrm{ng} / \mathrm{L}$ for all compounds at a concentration of $10 \mathrm{ng} / \mathrm{L}, \pm 0.66-11.4 \mathrm{ng} / \mathrm{L}$ at $50 \mathrm{ng} / \mathrm{L}$ and $\pm 0.64-19.8 \mathrm{ng} / \mathrm{L}$ for all compounds at a $100 \mathrm{ng} / \mathrm{L}$ concentration (Table 3).

Recoveries ranged from $77.6 \%$ to $106 \%$ at an analyte concentration of $50 \mathrm{ng} / \mathrm{L}$ and from $80.1 \%$ to $114 \%$ at $100 \mathrm{ng} / \mathrm{L}$ (Table 3 ).

Calculated $\mathrm{r}^{2}$-values were consistently above 0.97 indicating a strong linearity for all studied compounds over a range of 1-500 $\mu \mathrm{g} / \mathrm{L}$ for ethinylestradiol, $0.6-300 \mu \mathrm{g} / \mathrm{L}$ for BPA, 0.3-150 $\mu \mathrm{g} / \mathrm{L}$ for hydroxyacetophenone and $0.2-100 \mu \mathrm{g} / \mathrm{L}$ for all other compounds (Table 3).

Limits of detection ranged from $0.22 \mathrm{ng} / \mathrm{L}$ to $1.17 \mathrm{ng} / \mathrm{L}$ (amphetamine and ethinylestradiol respectively) and limits of quantification ranged from $0.75 \mathrm{ng} / \mathrm{L}$ to $4.91 \mathrm{ng} / \mathrm{L}$ (PFNA and ethinylestradiol respectively). Limits of detection/quantification are shown in Table 3.

\subsection{Occurrence of PPCPS/ECs in Sewage Treatment Effluent}

PPCPs and ECs were identified in every STW effluent (Table 4). It should be noted that summary statistics were calculated using all values found above the LOQ. Of the thirteen target compounds, eleven were detected in at least one sample, two (amphetamine and methamphetamine) were not detected in any sample. Detection frequencies ranged from $25 \%$ (ethinylestradiol) to $100 \%$ (benzoylecgonine, BPA, BPS and diclofenac). Table 4 shows concentrations and a basic statistical analysis of PPCPs/ECs detected in STW effluent outfalls. Across all studied compounds, the mean detection frequency was $78.5 \%$. BPA was 
found at a maximum level of $890 \mathrm{ng} / \mathrm{L}$ in STW 2 effluent which was significantly higher than any other studied compound in STW effluent outfalls (2.72 times higher than the next highest concentration).

Both BPA and its main biodegradation product 4'-hydroxyacetophenone (HAP) were typically found at the highest concentrations of any target contaminant in studied STW effluent outfalls. Except for STW 1, higher HAP/BPA ratios (possibly indicating greater inplant degradation of BPA into HAP) were observed in the effluent outfall of STWs using activated sludge treatment (HAP/BPA ratio 1.28-1.52) than STWs using trickling filter contact process (HAP/BPA ratio 0.14-0.22).

Of the pharmaceutical compounds detected, diclofenac was typically found at the highest concentration with an average of $62.2 \mathrm{ng} / \mathrm{L}$ (1.84 times that of the next highest pharmaceutical, acetaminophen). Of the three recreational drugs and urinary metabolites thereof, only benzoylecgonine was detected. Benzoylecgonine, a significant urinary metabolite of cocaine, was found in $100 \%$ of effluent samples with an average concentration of $9.20 \mathrm{ng} / \mathrm{L}$. Perfluorinated surfactants were detected with frequencies from 58.3\% (PFBS) to $91.7 \%$ (PFOA and PFNA). PFBS was detected at the highest average level of all PFCs (51.3 ng/L) while PFNA was detected at the highest maximum level of the PFCs $(209 \mathrm{ng} / \mathrm{L}$ in STW 4 effluent).

Daily loads of the compounds detected entering respective rivers via STW effluent outfalls (Table 5) ranged from $0.05 \mathrm{~g} /$ day (benzoylecgonine in STW 1 first collection) to 22.7 g/day (BPA in STW 2 second collection). On average, BPA showed the highest daily load between all STWs of $6.14 \mathrm{~g} /$ day which was 2.68 times that of the next highest, $2.29 \mathrm{~g}$ HAP/day (BPA's main biodegradation product). Except for STW 2, total daily loads of discharged PPCPs/ECs seemed to be correlated with the population equivalents of the respective STW facilities (see Supplementary Table 2 for STW characteristics, Table 5 for loads). STWs with higher population equivalents showed greater total daily loads of selected contaminants (except for STW 2).

\subsection{Occurrence of PPCPs/ECs in Street and Field Drainage}

Seven of the thirteen compounds monitored were identified in the drainage samples, all either plasticisers or PFCs: hydroxyacetophenone, BPS, BPA, PFBS, PFOA, PFNA and PFOS (Table 6). Street runoff into the River Bourne and the Blackwater River (inputs 1 and 2) showed the highest concentrations of target contaminants. Overall, field drainage showed both the lowest levels of detected contaminants and the lowest number of detected compounds/site (average 4.7 compounds/site detected in field drainage vs 6 compounds/site 
in street runoff). The highest measured concentration was of BPA $(2410 \mathrm{ng} / \mathrm{L})$ in street runoff into the River Bourne (Input 1), 2.7 times more concentrated than the highest detected level in STW effluent. PFOA and PFNA were also identified at maximum levels of $1160 \mathrm{ng} / \mathrm{L}$ and $647 \mathrm{ng} / \mathrm{L}$ in street runoff into the Blackwater River (Input 2) respectively which were 8.52 (PFOA) and 3.09 (PFNA) times higher than maximum respective levels found in STW effluent outfalls. Of the seven compounds detected in field drainage, average concentrations were from 3.14 times (BPA) to 24.9 times (PFBS) lower than average concentrations in STW effluent.

Compounds of human origin (pharmaceuticals and residues of recreational drugs) were not detected in any field drainage sample. An accurate average discharge volume of each drainage input was not possible to determine thus daily loads of detected contaminants were not evaluated in sampled runoffs.

\section{Discussion and Conclusion}

The presented SPE HPLC-MS/MS method can effectively and specifically quantify levels of the selected contaminants in water. The method was validated in-house using the ICH Harmonised Tripartite Guideline for Validation of Analytical Procedures: Q2(R1) Text and Methodology ( $\mathrm{ICH}, 2005)$. The presented method demonstrated that pharmaceuticals are not the only contaminants of ecological concern entering rivers via STW effluent discharge. Specifically, plasticisers and perfluorinated surfactants were detected at similar or higher levels than pharmaceuticals in STW effluent discharges. Plasticisers were found to be ubiquitous contaminants in all examined discharges into rivers (STW, field, and street runoff).

The type of sewage treatment used appears to have an effect on contaminant effluent levels of BPA. Higher ratios of HAP (BPA degradation product) to the BPA parent compound (HAP:BPA ratio) may indicate greater in-plant degradation of BPA into HAP. HAP:BPA ratios in the effluent of STWs using activated sludge ranged from 1.28 to 1.52 and were higher than those observed in plants using trickling filter contact where HAP:BPA ratios ranged from 0.14-0.22 (except for STW 2). This finding corroborates those found by Barber et al. (2012) where improved removal efficiency of endocrine disrupting compounds was observed in a sewage treatment facility in Boulder, Colorado (USA) after an upgrade from trickling filter contact to activated sludge treatment. However, contaminants of ecological concern are not solely introduced into the aquatic environment via STW effluent outfalls. 
During periods of rainfall, drainage from streets was found to contain PFCs and plasticisers at maximum levels, significantly higher (2.7 times for BPA, 3.09 times for PFNA and 8.52 times for PFOA) than their maximum levels in STW outfalls. It should be noted that the volume of street runoff (introduced into rivers via point-source drainage pipes) is highly variable and almost, if not always, exclusively less than the volume of a typical STW effluent discharge. Hence, the load of such contaminants entering rivers via street runoff is unknown, but may still be influential when considering the great number of such drainage point sources (albeit with lower relative flow rates) when compared to the number of STW effluent discharges along the course of a river. This is a finding that warrants further investigation.

Drainage from suburban fields into rivers was also found to contain small amounts of plasticisers and PFCs. Average concentrations were 3.14 to 24.9 times lower in field drainage than in STW effluent. Relatively low levels of plasticisers and PFCs entering river flow via field drainage may be explained by the presence of such chemicals in components of pipes used in channelling the discharge into rivers (U.S. Food and Drug Administration, 2015) or via their presence in the atmosphere (Huang et al., 2012; Liu et al., 2015).

Further work is warranted to elucidate the impact of street runoff on levels of plasticisers and perfluorinated compounds in receiving rivers. Here, limited samples were selected solely as reference to other sources of such contaminants and as a brief comparison to levels found in STW effluent discharges. Finding high levels of PFCs and plasticisers in street runoff is significant and should be further investigated. A study comparing first-flush rainfall discharges with time-weighted averages is particularly worth investigating.

\section{References}

Avendaño, S. M., \& Liu, J. (2015). Production of PFOS from aerobic soil biotransformation of two perfluoroalkyl sulfonamide derivatives. Chemosphere, 119, 1084-1090.

Barber, L., Vajda, A., Douville, C., Norris, D. and Writer J. (2012). Fish endocrine disruption responses to a major wastewater treatment facility upgrade. Environmental Science \& Technology, 46(4), 2121-2131.

Furl, C. V., Meredith, C. A., Strynar, M. J., \& Nakayama, S. F. (2011). Relative importance of wastewater treatment plants and non-point sources of perfluorinated compounds to Washington State rivers. Science of the Total Environment, 409(15), 2902-2907.

Huang, Y., Wong, C., Zheng, J., Bouwman, H., Barra, R., Wahlstrom, L., Neretin, L. and Wong, M. (2012). Bisphenol A (BPA) in China: a review of sources, environmental 
levels, and potential human health impacts. Environment International, 42(2012), 9199.

ICH, (2005). International Conference on Harmonisation, Harmonised Tripartite Guideline Validation of Analytical Procedures: Text and Methodology Q2(R1), [pdf], [last accessed 31 May 2016], available at:

$<$ http://www.ich.org/fileadmin/Public_Web_Site/ICH_Products/Guidelines/Quality/Q2 _R1/Step4/Q2_R1_Guideline.pdf>.

Jjemba, P.K. (2006). Excretion and ecotoxicity of pharmaceutical and personal care products in the environment, Ecotoxicology and Environmental Safety, 63(1), 113-130.

King, O. C., van de Merwe, J. P., McDonald, J. A., \& Leusch, F. D. (2015). Concentrations of levonorgestrel and ethinylestradiol in wastewater effluents: is the progestin also cause for concern? Environmental Toxicology and Chemistry, 35(6), 1378-1385.

Kolpin, D. W., Furlong, E. T., Meyer, M. T., Thurman, E. M., Zaugg, S. D., Barber, L. B., \& Buxton, H. T. (2002). Pharmaceuticals, hormones, and other organic wastewater contaminants in US streams, 1999-2000: A national reconnaissance. Environmental Science \& Technology, 36(6), 1202-1211.

Liu, B., Zhang, H., Yao, D., Li, J., Xie, L., Wang, X., Wang, X, Liu, G. and Yang, B. (2015). Perfluorinated compounds (PFCs) in the atmosphere of Shenzhen, China: Spatial distribution, sources, and health risk assessment. Chemosphere, 138(2015), 511-518.

Llorca, M., Farré, M., Picó, Y., Müller, J., Knepper, T.P. \& Barceló, D. (2012). Analysis of perfluoroalkyl substances in waters from Germany and Spain. Science of the Total Environment, 431, 139-150.

Meyer, J., \& Bester, K. (2004). Organophosphate flame retardants and plasticisers in wastewater treatment plants. Journal of Environmental Monitoring, 6(7), 599-605.

Murakami, M., Shinohara, H., \& Takada, H. (2009). Evaluation of wastewater and street runoff as sources of perfluorinated surfactants (PFSs). Chemosphere, 74(4), 487-493.

Patisaul, H.B. \& Adewale, H.B. (2009). Long-term effects of environmental endocrine disruptors on reproductive physiology and behavior. Frontiers in Behavioral Neuroscience, $3,10$.

Peck, A. (2006). Analytical methods for the determination of persistent ingredients of personal care products in environmental matrices. Analytical and Bioanalytical Chemistry, 386(4), 907-939. 
Petrie, B., Barden, R., \& Kasprzyk-Hordern, B. (2015). A review on emerging contaminants in wastewaters and the environment: Current knowledge, understudied areas and recommendations for future monitoring. Water Research, 72, 3-27.

Posner, S. (2012). Perfluorinated compounds: occurrence and uses in products. In Polyfluorinated Chemicals and Transformation Products (pp. 25-39). Springer Berlin Heidelberg.

Raghav M, Eden S, Katharine M, Witte B. 2013. Contaminants of emerging concern in water. Tucson, USA: University of Arizona, Water Resources Research Center, [pdf], [Last accessed 16 March, 2016], available at:

$<$ http://arizona.openrepository.com/arizona/bitstream/10150/325905/3/Arroyo_2013.pdf $>$.

Roosens, L., Covaci, A. \& Neels, H. (2007). Concentrations of synthetic musk compounds in personal care and sanitation products and human exposure profiles through dermal application. Chemosphere, 69(10), 1540-1547.

Silva, B.F.d., Jelic, A., López-Serna, R., Mozeto, A.A., Petrovic, M. \& Barceló, D. (2011). Occurrence and distribution of pharmaceuticals in surface water, suspended solids and sediments of the Ebro river basin, Spain. Chemosphere, vol. 85(8), 1331-1339.

U.S. Food and Drug Administration (2015). Bisphenol A (BPA): Use in food contact application, [online], [Last accessed 23 Nov 2015], available at: $<$ http://www.fda.gov/NewsEvents/PublicHealthFocus/ucm064437.htm>.

United States Geological Survey, 2014. Emerging contaminants in the environment [Homepage of U.S. Department of the Interior], [Online]. Available: $<$ http://toxics.usgs.gov/regional/emc/> [Last accessed: 16 March, 2016].

Vajda, A.M., Barber, L.B., Gray, J.L., Lopez, E.M., Bolden, A.M., Schoenfuss, H.L. \& Norris, D.O. (2011). Demasculinization of male fish by wastewater treatment plant effluent. Aquatic Toxicology, 103(3), 213-221.

Vajda, A.M., Barber, L.B., Gray, J.L., Lopez, E.M., Woodling, J.D. \& Norris, D.O. (2008). Reproductive disruption in fish downstream from an estrogenic wastewater effluent. Environmental Science \& Technology, 42(9), 3407-3414.

Verlicchi, P., Al Aukidy, M., \& Zambello, E. (2012). Occurrence of pharmaceutical compounds in urban wastewater: removal, mass load and environmental risk after a secondary treatment - a review. Science of the Total Environment, 429, 123-155. 
Wilkinson, J. L., Hooda, P. S., Barker, J., Barton, S., \& Swinden, J. (2015). Ecotoxic pharmaceuticals, personal care products, and other emerging contaminants: A review of environmental, receptor-mediated, developmental, and epigenetic toxicity with discussion of proposed toxicity to humans. Critical Reviews in Environmental Science and Technology, 46(4), 336-381.

Woodling, J.D., Lopez, E.M., Maldonado, T.A., Norris, D.O. \& Vajda, A.M. (2006). Intersex and other reproductive disruption of fish in wastewater effluent dominated Colorado streams. Comparative Biochemistry and Physiology Part C: Toxicology \& Pharmacology, 144(1), 10-15.

Zhang, W., Zhang, Y., Taniyasu, S., Yeung, L. W., Lam, P. K., Wang, J., Li, X., Yamashita, N. \& Dai, J. (2013). Distribution and fate of perfluoroalkyl substances in municipal wastewater treatment plants in economically developed areas of China. Environmental Pollution, 176, 10-17.

Zushi, Y., Takeda, T., \& Masunaga, S. (2008). Existence of nonpoint source of perfluorinated compounds and their loads in the Tsurumi River basin, Japan. Chemosphere, 71(8), 1566-1573. 


\subsection{Tables and Figures}

Table 1- Ion Fragmentation and Spectrometer Conditions

\begin{tabular}{|c|c|c|c|c|c|c|c|}
\hline $\begin{array}{l}\text { Compound } \\
\text { Type }\end{array}$ & Compound & $\begin{array}{l}\text { Precursor } \\
\text { Ion Mass } \\
\text { (amu) }\end{array}$ & Polarity & $\begin{array}{l}\text { Quantifier } \\
\text { Ion Mass } \\
\text { (T1) }\end{array}$ & $\begin{array}{l}\text { Qualifier } \\
\text { Ion Mass } \\
\text { (T2) }\end{array}$ & Fragmentor & $\begin{array}{c}\text { Collision } \\
\text { Energy } \\
(\mathrm{eV}) \\
(\mathrm{T} 1, \mathrm{~T} 2) \\
\end{array}$ \\
\hline \multirow{4}{*}{$\begin{array}{l}\text { Perfluorinated } \\
\text { Compounds }\end{array}$} & PFBS & 298.8 & Negative & 80.0 & 99.0 & 128 & 30,24 \\
\hline & PFNA & 462.9 & Negative & 419.0 & 219.0 & 92 & 4,8 \\
\hline & PFOA & 412.9 & Negative & 369.0 & 169.0 & 100 & 4,8 \\
\hline & PFOS & 498.4 & Negative & 80.0 & 99.0 & 180 & 30,30 \\
\hline \multirow[t]{3}{*}{ Pharmaceuticals } & Acetominophen & 152.1 & Positive & 110.3 & 65.3 & 92 & 12,30 \\
\hline & Diclofenac & 293.9 & Negative & 250.0 & 214.0 & 56 & 4,12 \\
\hline & Ethinylestradiol & 295.5 & Positive & 133.0 & 199.5 & 92 & 20,12 \\
\hline \multirow[t]{3}{*}{ Plasticisers } & Bisphenol-A & 227.1 & Negative & 212.1 & 133.1 & 116 & 12,20 \\
\hline & Bisphenol-S & 249.0 & Negative & 108.1 & 92.1 & 132 & 24,30 \\
\hline & 4'-Hydroxyacetophenone & 135.0 & Negative & 92.1 & 120.0 & 100 & 24,12 \\
\hline \multirow{3}{*}{$\begin{array}{l}\text { Recreational } \\
\text { Drugs }\end{array}$} & Amphetamine & 136.1 & Positive & 119.1 & 91.0 & 66 & 5,17 \\
\hline & Benzoylecgonine & 290.1 & Positive & 168.3 & 105.2 & 92 & 16,30 \\
\hline & Methamphetamine & 150.1 & Positive & 91.0 & 65.1 & 92 & 17,45 \\
\hline \multirow{3}{*}{$\begin{array}{l}\text { Internal } \\
\text { Standards }\end{array}$} & Acetominophen-D4 & 156.1 & Positive & 114.4 & 69.4 & 100 & 12,32 \\
\hline & Bisphenol A-D16 & 241.1 & Negative & 141.8 & 233.0 & 130 & 38,13 \\
\hline & Methamphetamine-D5 & 155.1 & Positive & 121.1 & 91.1 & 95 & 54,17 \\
\hline
\end{tabular}

T1- Transition ion $1 \quad$ T2- Transition ion 2 
Table 2- Intra-/Inter-day Repeatability/Precision

\begin{tabular}{|c|c|c|c|c|c|c|c|c|}
\hline \multirow[t]{3}{*}{ Compound } & \multicolumn{5}{|c|}{ Intra-day RSD (\%) } & \multirow[b]{3}{*}{ Day 3} & \multicolumn{2}{|c|}{ Inter-day RSD (\%) } \\
\hline & \multirow[b]{2}{*}{ Day 1} & \multicolumn{2}{|l|}{$25 \mathrm{ng} / \mathrm{L}$} & \multirow[b]{2}{*}{ Day 1} & $100 \mathrm{ng} / \mathrm{L}$ & & \multirow[t]{2}{*}{$25 \mathrm{ng} / \mathrm{L}$} & \multirow[t]{2}{*}{$100 \mathrm{ng} / \mathrm{L}$} \\
\hline & & Day 2 & Day 3 & & Day 2 & & & \\
\hline 4'-Hydroxyacetophenone & 5.92 & 10.5 & 12.3 & 7.47 & 8.99 & 4.03 & 9.57 & 6.83 \\
\hline Acetaminophen & 5.73 & 7.4 & 12.4 & 6.01 & 3.82 & 6.48 & 8.53 & 5.44 \\
\hline Amphetamine & 3.91 & 7.13 & 5.48 & 9.48 & 9.37 & 5.44 & 5.51 & 8.10 \\
\hline Benzoylecgonine & 7.83 & 10.5 & 7.99 & 4.58 & 3.42 & 4.14 & 8.78 & 4.05 \\
\hline BPA & 5.04 & 6.56 & 3.37 & 3.67 & 3.43 & 3.91 & 4.99 & 3.67 \\
\hline BPS & 3.06 & 4.71 & 4.00 & 4.10 & 1.74 & 4.34 & 3.92 & 3.40 \\
\hline Diclofenac & 6.01 & 6.10 & 4.75 & 6.34 & 4.87 & 6.66 & 5.62 & 5.96 \\
\hline Ethinylestradiol & 9.54 & 8.57 & 9.92 & 9.33 & 8.59 & 8.89 & 9.34 & 8.94 \\
\hline Methamphetamine & 6.79 & 9.93 & 10.1 & 12.4 & 9.28 & 13.7 & 8.95 & 11.8 \\
\hline PFBS & 6.65 & 4.63 & 9.76 & 6.62 & 4.66 & 7.20 & 7.01 & 6.16 \\
\hline PFNA & 2.24 & 3.15 & 2.62 & 3.19 & 1.77 & 3.28 & 2.67 & 2.75 \\
\hline PFOA & 3.05 & 4.37 & 2.78 & 3.72 & 2.07 & 3.74 & 3.40 & 3.17 \\
\hline PFOS & 5.64 & 3.75 & 6.72 & 5.11 & 3.09 & 2.18 & 5.37 & 3.46 \\
\hline
\end{tabular}


Table 3- Method validation results

\begin{tabular}{|c|c|c|c|c|c|c|c|c|c|}
\hline \multirow[t]{2}{*}{ Compound } & \multirow[t]{2}{*}{ pKa } & \multicolumn{3}{|c|}{ Accuracy (ng/L) } & \multicolumn{2}{|c|}{$\underline{\operatorname{Recovery}(\%)}$} & \multirow{2}{*}{$\begin{array}{l}\underline{\text { Linearity }} \\
\mathrm{r}^{2} \text {-value }\end{array}$} & \multicolumn{2}{|c|}{ Det./Quant. Limits } \\
\hline & & $\begin{array}{r}10 \mathrm{ng} / \mathrm{L} \\
(+/-)\end{array}$ & $\begin{array}{r}50 \mathrm{ng} / \mathrm{L} \\
(+/-)\end{array}$ & $\begin{array}{r}0 \mathrm{ng} / \mathrm{L} \\
(+/-)\end{array}$ & $50 \mathrm{ng} / \mathrm{L}$ & $100 \mathrm{ng} / \mathrm{L}$ & & $\begin{array}{r}\text { LOD } \\
(\mathrm{ng} / \mathrm{L})\end{array}$ & $\begin{array}{r}\mathrm{LOQ} \\
(\mathrm{ng} / \mathrm{L}) \\
\end{array}$ \\
\hline 4'-Hydroxyacetophenone & 8.12 & 0.91 & 3.96 & 16.8 & 92.1 & 83.2 & 0.987 & 0.31 & 1.04 \\
\hline Acetaminophen & 9.38 & 1.47 & 4.9 & 6.71 & 90.2 & 93.3 & 0.973 & 0.28 & 0.93 \\
\hline Amphetamine & 10.1 & 2.15 & 9.91 & 16.6 & 80.2 & 83.4 & 0.969 & 0.22 & 1.09 \\
\hline Benzoylecgonine & $3.15-9.54$ & 2.1 & 11.4 & 19.8 & 77.2 & 80.1 & 0.997 & 0.31 & 1.02 \\
\hline Bisphenol-A & 10.3 & 0.15 & 2.89 & 13.9 & 105 & 113 & 0.994 & 1.17 & 3.87 \\
\hline Bisphenol-S & 8.2 & 2.4 & 11.2 & 15.7 & 77.6 & 84.3 & 0.993 & 0.34 & 3.87 \\
\hline Diclofenac & 4.15 & 0.41 & 0.66 & 4.43 & 101 & 104 & 0.986 & 0.29 & 0.96 \\
\hline Ethinylestradiol & 10.7 & 1.49 & 5.16 & 9.67 & 89.7 & 90.3 & 0.971 & 0.98 & 4.91 \\
\hline Methamphetamine & 9.87 & 0.03 & 3.47 & 9.68 & 93.1 & 90.3 & 0.988 & 0.32 & 1.06 \\
\hline Perfluorobutanesulfonic Acid & $<1$ & 1.1 & 1.84 & 6.86 & 103 & 93.1 & 0.974 & 0.33 & 1.13 \\
\hline Perfluorononanoic Acid & $<1$ & 1.13 & 3.34 & 0.64 & 93.3 & 101 & 0.993 & 0.23 & 0.75 \\
\hline Perfluorooctanoic Acid & $<1$ & 1.04 & 1.63 & 2.32 & 103 & 97.7 & 0.997 & 0.34 & 1.13 \\
\hline Perfluorooctane Sulfonate & $<1$ & 1.46 & 4.97 & 0.27 & 90.1 & 99.7 & 0.989 & 0.51 & 1.52 \\
\hline
\end{tabular}

LOD- Limit of detection, LOQ- Limit of quantification 
Table 4- STW information and concentrations (ng/L) of PPCPs/ECs detected in STW effluents $(n=12)$ with basic statistical analysis

\begin{tabular}{|c|c|c|c|c|c|c|c|c|c|c|c|}
\hline & $\begin{array}{c}\text { Effluent } \\
1 \\
\end{array}$ & $\begin{array}{c}\text { Effluent } \\
2 \\
\end{array}$ & $\begin{array}{c}\text { Effluent } \\
\mathbf{3} \\
\end{array}$ & $\begin{array}{c}\text { Effluent } \\
4 \\
\end{array}$ & $\begin{array}{c}\text { Effluent } \\
5 \\
\end{array}$ & $\begin{array}{c}\text { Effluent } \\
6 \\
\end{array}$ & \multirow[b]{6}{*}{$\begin{array}{l}\text { Mean } \\
(\mathrm{ng} / \mathrm{L})\end{array}$} & \multirow[b]{6}{*}{$\begin{array}{c}\text { Det. Freq. } \\
(\%)\end{array}$} & \multirow[b]{6}{*}{$\operatorname{Max}(n g / L)$} & \multirow[b]{6}{*}{$\mathrm{SD}(\mathrm{ng} / \mathrm{L})$} & \multirow[b]{6}{*}{ RSD (\%), } \\
\hline Population Equivalent & 383,000 & 86,800 & 37,000 & 140,000 & 34,300 & 88,400 & & & & & \\
\hline Average daily flow $\left(\mathrm{m}^{3}\right)$ & 58,180 & 25,534 & 10,073 & 31,196 & 9,098 & 24,795 & & & & & \\
\hline Average flow $\left(\mathrm{m}^{3} / \mathrm{sec}\right)$ & 0.673 & 0.296 & 0.117 & 0.361 & 0.105 & 0.287 & & & & & \\
\hline Treatment & AST & AST/TFC* & AST & AST & TFC & TFC & & & & & \\
\hline Compound (ng/L) & & & & & & & & & & & \\
\hline 4'-Hydroxyacetophenone & 13.1 & 213 & 150 & 144 & 11.8 & 58.5 & 98.4 & 91.7 & 327 & 82.8 & 84.1 \\
\hline Acetaminophen & 17.5 & 133 & 17.3 & 10.3 & 5.63 & 19.1 & 33.8 & 91.7 & 157 & 48.9 & 145 \\
\hline Amphetamine & ND & ND & ND & ND & ND & ND & ND & 0 & ND & & \\
\hline Benzoylecgonine & 1.09 & 19.9 & 10.8 & 7 & 4.61 & 11.9 & 9.2 & 100 & 25.7 & 6.57 & 71.4 \\
\hline $\mathrm{BPA}$ & 216 & 488 & 98.5 & 113 & 82.1 & 264 & 210 & 100 & 891 & 154 & 73.2 \\
\hline BPS & 5.76 & 201 & 25 & 34.2 & 9.71 & 4.13 & 46.5 & 100 & 306 & 76.6 & 165 \\
\hline Diclofenac & 76.2 & 31.5 & 102 & 98.3 & 38.9 & 26.2 & 62.2 & 100 & 201 & 34.2 & 55 \\
\hline Ethinylestradiol & ND & 5.11 & $<$ LOQ & 3.75 & ND & ND & 4.43 & 25 & 10.2 & 3.48 & 78.6 \\
\hline Methamphetamine & ND & ND & ND & ND & ND & ND & ND & 0 & ND & & \\
\hline PFBS & 9.64 & 21 & 57.6 & 92.3 & 96 & 31.3 & 51.3 & 58.3 & 115 & 36.8 & 71.7 \\
\hline PFNA & 6.03 & 5.48 & 91.9 & 113 & 14.9 & 19.4 & 41.8 & 91.7 & 209 & 47.8 & 114 \\
\hline PFOA & 19.9 & 22.2 & 21.1 & 3.89 & 36.3 & 87.1 & 31.7 & 91.7 & 136 & 28.9 & 91.4 \\
\hline PFOS & 60.1 & 31.4 & 22.2 & 19.8 & 3.46 & 56.1 & 32.2 & 83.3 & 115 & 22.1 & 68.5 \\
\hline
\end{tabular}

*Combination of Trickling Filter Contact (TFC) and Activated Sludge Treatment (AST)

ND- Not Detected 
Table 5- Range of compound loads (g/day) entering receiving rivers via respective STW effluent outfalls ( $\mathrm{n}=12$ )

\begin{tabular}{|l|cccccc|c|}
\multicolumn{1}{|c}{ Compound (g/day) } & STW 1 & STW 2 & STW 3 & STW 4 & STW 5 & STW 6 & Mean (g/day) \\
\hline 4'-Hydroxyacetophenone & $0.35-1.17$ & $2.51-8.36$ & $0.03-2.99$ & ND-9.00 & $0.03-0.19$ & $0.50-2.40$ & 2.29 \\
Acetominophen & $0.92-1.11$ & $2.80-4.01$ & $0.11-0.24$ & $0.14-0.50$ & $0.01-0.10$ & ND-2.95 & 0.91 \\
Amphetamine & ND & ND & ND & ND & ND & ND & 0 \\
Benzoylecgonine & $0.05-0.07$ & $0.36-0.66$ & $0.03-0.18$ & $0.14-0.30$ & $0.02-0.06$ & $0.18-0.41$ & 0.21 \\
BPA & $1.09-24.1$ & $2.17-22.7$ & $0.25-1.74$ & $2.50-4.55$ & $0.20-1.29$ & $5.98-7.09$ & 6.14 \\
BPS & $0.13-0.54$ & $2.46-7.82$ & $0.02-0.49$ & $0.06-2.07$ & $0.01-0.16$ & $0.06-0.14$ & 1.16 \\
Diclofenac & $4.02-4.85$ & $0.09-1.52$ & $0.03-2.02$ & $0.11-6.02$ & $0.14-0.67$ & $0.40-1.30$ & 1.72 \\
Ethinylestradiol & ND & ND-0.29 & ND & ND-0.23 & ND & ND & 0.04 \\
Methamphetamine & ND & ND & ND & ND & ND & ND & 0 \\
PFBS & $0.26-0.86$ & ND-1.07 & ND-1.16 & ND-2.88 & ND-0.87 & ND-1.50 & 1.03 \\
PFNA & $0.16-0.55$ & $0.07-0.21$ & $0.29-1.56$ & $0.52-6.53$ & ND-0.14 & $0.40-0.56$ & 0.93 \\
PFOA & $0.53-1.78$ & $0.26-0.87$ & $0.13-0.29$ & ND-0.24 & $0.19-0.47$ & $0.94-3.37$ & 0.76 \\
PFOS & $0.29-6.70$ & $0.10-1.51$ & ND- 0.45 & ND- 0.62 & ND-0.03 & $0.20-2.59$ & 1.09 \\
\hline Mean sum of all (g/day) & 24.8 & 29.9 & 6.01 & 19.9 & 2.76 & 14.3 & 16.3 \\
\hline
\end{tabular}


Table 6- Concentrations of PPCP/ECs detected in street runoff and field drainage prior to entering rivers

\begin{tabular}{|l|cc|ccc|} 
Compound & \multicolumn{2}{|c|}{ treet Runoff (ng/L) } & \multicolumn{3}{c|}{ Field Drainage (ng/L) } \\
\cline { 2 - 6 } & Input 1 & Input 2 & Input 3 & Input 4 & Input 5 \\
\hline 4'-Hydroxyacetophenone & 48.4 & 254 & 5.98 & 16.5 & 16.7 \\
Acetominophen & ND & ND & ND & ND & ND \\
Amphetamine & ND & ND & ND & ND & ND \\
Benzoylecgonine & ND & ND & ND & ND & ND \\
Bisphenol-A & 2410 & 511 & 54.2 & 45.6 & 101 \\
Bisphenol-S & 50.2 & 40.6 & 2.27 & 4.42 & 159 \\
Diclofenac & ND & ND & ND & ND & ND \\
Ethinylestradiol & ND & ND & ND & ND & ND \\
Methamphetamine & ND & ND & ND & ND & ND \\
PFBS & 79.1 & ND & ND & ND & 6.19 \\
PFNA & 69.2 & 648 & ND & 23.0 & 2.01 \\
PFOA & 6.52 & 1160 & ND & 15.5 & ND \\
PFOS & 8.97 & ND & ND & ND & 6.57 \\
\hline
\end{tabular}




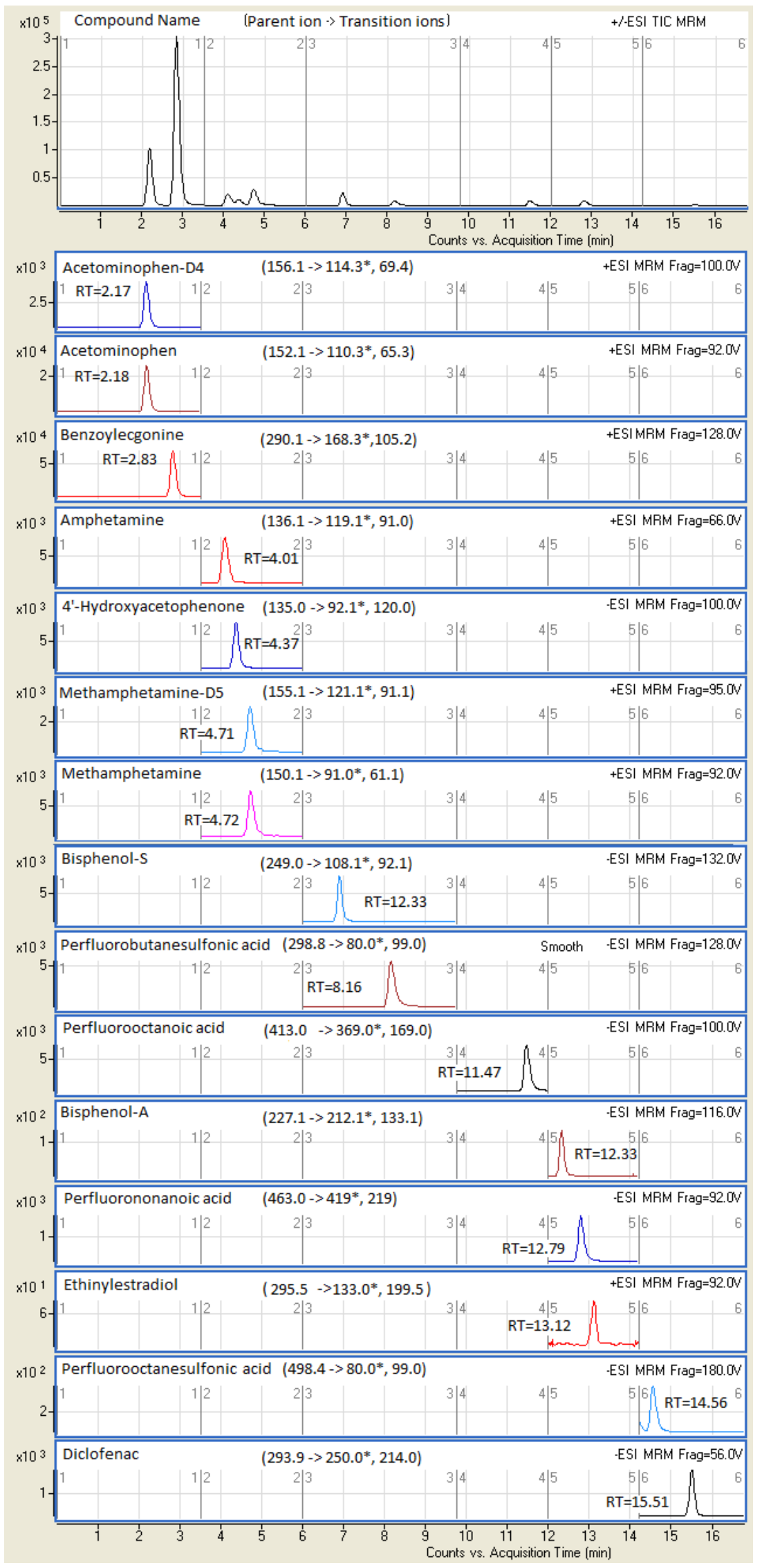

*Quantifying transition ion

Figure 1- Chromatogram of target PPCP/ECs 